\title{
LA LOCURA DE DON QUIJOTE. IDEOLOGÍA Y LITERATURA EN LA NOVELA CERVANTINA *
}

Para Rogelio Reyes, con quien es tan grato charlar de locos y poetas de otras épocas.

\section{Don Quijote y el tema de la locura}

El tema literario de la locura está aún necesitado de estudio. El profesor Rogelio Reyes, basándose en cuentecillos de esa época, ha realizado una lúcida y sucinta aproximación a este aspecto recientemente, señalando su relación con la sátira grecolatina del mundo del revés y su inversión de valores, heredada por los renacentistas ${ }^{1}$.

El libro de Martine Bigeard, ya antiguo, de 1972, realiza un viaje al mundo de la locura en la literatura española entre 1500 y 1650 , redactado con sencillez que esconde una buena documentación, interesante y bien escrito, no llena sin embargo todas las expectativas que este tema contiene, aunque constituya una buena aproximación general y divulgativa ${ }^{2}$.

Especial mención merece el apéndice dedidado a «La locura de Don Quijote» por Vicente Gaos en el volumen tercero de su edición del libro (1987), de una gran agudeza crítica ${ }^{3}$ :

* El presente trabajo se gestó en la Universidad de California en Santa Bárbara en verano de 1996, donde estuve - como en otras ocasiones - trabajando con Juan Bautista Avalle-Arce, ese año con una beca del Ministerio de Educación y Ciencia para estancia en centros extranjeros. Quiero manifestar mi agradecimiento al profesor Avalle-Arce y al Ministerio que concedió la ayuda, sirviendo este artículo de primera aproximación a lo que espero constituya algún día un libro más extenso.

1 Rogelio ReYes, «'Predicadores locos', 'locos predicadores' y 'locos agudos' en la literatura española del Siglo de Oro: los cuentecillos de Juan García», en Philologica (Homenaje al profesor Ricardo Senabre). Salamanca, 1997, pp. 461-80.

2 MARTINe Bigeard, La folie et les fous littéraires en Espagne, 1500-1650. París, Centre de Recherches Hispaniques, 1972, pp. 153-64 sobre El Quijote.

3 Miguel de Cervantes SaAvedra, $D Q M$, ed. de Vicente GaOs, Madrid, Gredos, 1987, vol. III Apéndices, "La locura de DQ", pp. 162-88. Esta cita en p. 162, n. 1. 
«Los psiquiatras y otros críticos que juzgan a Don Quijote esquizofrénico, paranoico, etc., se den o no cuenta de ello, incurren en el mismo error del personaje que estudian: confunden realidad y ficción (...)».

Y añade más tarde ${ }^{4}$ :

«En el Quijote —único lugar donde en rigor cabe estudiarla- la locura del protagonista es, ante todo, un recurso técnico, un motivo funcional y estructurante de la novela. Si Don Quijote no estuviera loco, no habría Quijote (...)».

Es una pena que la gran inteligencia crítica de Gaos caiga en una anotación tan deudora del estado de la cuestión, cuando podría haberse aventurado con mayor frecuencia en interpretaciones de sentido. Con todo, su edición es la de un humanista, un pensador y un lírico simultáneamente, y es necesario rescatarla de nuevo. No puede nunca congeniar con el criticismo logicista, cientifista y estadístico - que también supone una aportación, en el otro extremo- de la «spelling edition» de Flores por ejemplo. Ambas visiones se complementan. Lo que mi admirado amigo el profesor Avalle-Arce achacó a Gaos no expresa sino una diferencia profunda de concepción crítica ante El Quijote. Pero ambas formas de crítica se complementan y pueden coexistir sin exclusiones ${ }^{5}$.

Por otra parte el estudio del tema de la locura en relación a la literatura ha sido objeto recientemente de numerosos trabajos ${ }^{6}$.

Fundamentalmente el tratamiento de este tema de la locura cervantina se ha relacionado con la obra de Erasmo, aspecto éste que sólo trataré tangencialmente en lo que atañe a mi objetivo.

En un espléndido libro reeditado ampliado recientemente, Antonio Vilanova se refiere al tema de el Elogio de la locura en rela-

4 Op. cit., p. 162.

5 Hay otras muchísimas entradas bibliográficas sobre nuestro tema que podrían ser aquí aludidas. Seleccionaré de entre ellas la lectura psicoanalítica y lacaniana de la obra cervantina compilada por RUTH ANTHONY El SAFFAR y DiANE DE ARMAS Wilson, Quixotic Desire. Psychoanalytic Perspectives on Cervantes. Ithaca and London, Cornell University Press, 1993.

6 Cfr., por ej., de Rogelio REyes CANo, "Otra muestra de la literatura del loco en el Renacimiento español: el caso de Cristóbal de Castillejo», NRFH, XXXIV, 19851982, 2, pp. 808-38; "Los sermones de Amaro Rodríguez, un ejemplo de la literatura del loco en la Sevilla del Siglo de Oro», en Homenaje a Alonso Zamora Vicente, III, 2. Madrid, Castalia, 1992, pp. 277-94, ampliado en Demencia y literatura en la Sevilla del siglo XVII: los 'Sermones' del loco Amaro. Discurso leído ante de real Academia Sevillana de Buenas Letras, Sevilla, 1992.

Una bibliografía muy actualizada del tema de la locura y la literatura se encuentra en Francisco Márouez Villanueva, Trabajos y días cervantinos. Alcalá de Henares, Centro de Estudios Cervantinos, 1995 (Biblioteca de Estudios Cervantinos), p. 23, n. 1. Remito a ella. 
ción a Cervantes ${ }^{7}$. Frente a la tesis de Bataillon ${ }^{8}$ de que Cervantes era un erasmista que no leyó a Erasmo, salvo los Apotegmas y los Adagia, y con conocimientos al respecto de segunda mano, Vilanova indica que los elementos de la locura quijotesca están en el Elogio de la locura. Esta obra de Erasmo presenta una sátira del mundo como escenario de la cultura universal y la locura como elemento indispensable para hacer posible la vida humana. La felicidad estriba en la locura, pues el loco vive en la ficción, de donde su ventura.

Vilanova sostiene que Cervantes se inspira en el Elogio de la locura para su novela. Pudo conocer la versión italiana de 1539 editada en Venecia en traducción de Antonio Pellegrini. Y la imitación de Jerónimo de Mondragón Censura de la locura humana y Excelencias de ella (Lérida, 1598), aunque como vimos Bataillon niega en concreto estos asertos.

Habría que aludir finalmente al libro de Francisco Márquez Villanueva Trabajos y días cervantinos (1995) ${ }^{9}$. Cervantes aprendería de Erasmo el arte nuevo del disparate, pero esta vez de esencia irónica. Y se refiere a la locura bufonesca en el humanismo cristiano.

\section{Anfibiología de la locura erasmiana}

Poco a poco vamos a ir entrando ahora en la parte más personal del trabajo que el lector tiene en las manos, y en la que no he querido aventurarme sin realizar estas precisiones inciales.

Poseemos una espléndida traducción del Elogio de la locura por Oliveri Nortes Valls (1976), que utilizaré ${ }^{10}$. En su estudio preliminar Nortes se refiere con amplia bibliografía a la tradición acerca de la locura previa a Erasmo, la costumbre medieval del «carro de los locos» y la «nave de los locos» en el carnaval de las calles, la obra de Sebastian Brant Das Narrenschiff (El barco de los locos) escrita en 1492 y publicada en traducción latina de 1497. Es el

7 Antonio Vilanova, Erasmo y Cervantes. Barcelona, Lumen, 1989. La parte fundamental de este libro está constituida por un largo trabajo de 1949, aunque está considerablemente ampliado con otros, igualmente de singular valor.

8 Marcel Bataillon, Erasmo y el erasmismo. Barcelona, Crítica, 1983, 2. a ed. $\left(1 .^{a}, 1978\right)$, «Un problema de la influencia de Erasmo en España. El Elogio de la locura", pp. 327-47. Es un trabajo inicialmente publicado en 1971 y difundido en 1969.

9 Francisco Márouez Villanueva, Trabajos y días cervantinos. Alcalá de Henares, Centro de Estudios Cervatinos, 1995 (Biblioteca de Estudios Cervantinos, 2).

10 D. ERASmo DE RotTerdam, Elogio de la locura, intr., trad. y notas de Oliveri Nortes Valls. Barcelona, Bosch, 1976 (Col. Erasmo, Textos bilingües). 
aspecto bufo y carnavalesco, la liberación de pasiones en una jornada.

Vayamos ya a nuestra propia argumentación. Me parece que $E l$ Quijote se fundamenta en el repaso irónico de la sociedad, que aparece previamente en la obra de Erasmo. Pero Don Quijote no es un tonto sino todo lo contrario, un idealista inteligente, cuya locura, por tal, se parodia. En la obra de Cervantes, poco a poco, de la parodia se va pasando al admirativo dibujo de un personaje único en la literatura de todos los tiempos. Lo que se inicia como parodia, acaba por constituir un panegírico, en el contraste violento de la personalidad del idealista con la realidad con la que choca. Cervantes eleva la parodia a la categoría de lo sublime.

Pero salvo este aspecto de repaso irónico de la sociedad, y sin inconveniente para admitir en otros aspectos huellas erasmianas en Cervantes, aunque Bataillon, Vilanova y Márquez Villanueva hayan dirigido sus esfuerzos hacia una relación con el Elogio de la locura, creo que la locura de Don Quijote no tiene que ver con la de Erasmo, que es más bien una bufonesca y lúdica «necedad», alegre y carnavalesca. Cervantes tampoco compartiría por ejemplo la crítica de la obra de Erasmo a la mujer ${ }^{11}$, pues nuestro escritor es más progresista y moderno, equitativo ante el tema femenino incluso cuando toca el tema de la posadera libertina. Tampoco compartiría la crítica del matrimonio que aparece en el texto de Erasmo ${ }^{12}$.

Erasmo intenta demostrar la bondad de la necedad frente a la pesada sabiduría hosca y aburrida. Se trata de un libro lleno de sorna y maravillosamente bien escrito. Lo que trata de mostrar es el imperio de la estupidez en el mundo y la sociedad, y en este sentido está muy lejos del Quijote.

Hay en la obra de Erasmo constantes ironías, por ejemplo cuando se presenta al sabio como un inadaptado en la vida social de los estultos ${ }^{13}$. La vida aparece como una comedia. En realidad el libro de Erasmo, cargado de dobles sentidos, constituye la visión de un sabio acerca de la necedad humana, que ensalza humorísticamente, cuando en realidad quiere decir lo contrario de lo que irónicamente afirma.

Pero notemos un aspecto importantísimo. Locura es dementia en latín, no stultitia (estulticia) ${ }^{14}$. Por tanto Erasmo no se refiere generalmente a la locura como tal, sino a la necedad, que es la que critica y ridiculiza, junto a la convención social.

11 Cfr. Elogio de la locura, ed. cit., cap. XVII, pp. 125-29.

12 Cfr. Elogio..., XX, pp. 135-37.

13 Elogio..., op. cit., XXV, pp. 145-49.

14 Elogio..., op. cit., p. 174. 
Además debo insistir en que este libro de Erasmo quiere decir - salvo en la parte final, con su clara crítica de la religión oficiallo contrario de lo que dice, con una gran ironía. Por eso concluye, ante el imperio universal de la estupidez — que no de la locura, insisto- en que los más desdichados son los sabios, y los menos los brutos y los necios ${ }^{15}$.

La obra de Erasmo es de sumo interés para una persona creyente de hoy en día, por su visión crítica y certera, por su aproximación directa y auténtica al tema religioso. Aún puede leerse con aprovechamiento.

Erasmo no deja títere con cabeza. Por ello hace tanto una sátira del intelectual como una burla del ignorante. Los estúpidos, afirma, son los que dicen la verdad ${ }^{16}$. Pero separa siempre estupidez - stultitia, la actitud vital del ignorante- y locura -insania- ${ }^{17}$.

En un determinado momento Erasmo define la locura, lo que me parece importante por el reflejo que pudiera haber en El Quijote ${ }^{18}$ :

«Pero si alguien yerra no sólo en sus sentidos, sino en las apreciaciones de su razón, y si tal cosa ocurriera más de lo habitual o continuamente, a ése precisamente habrá que considerarlo dado a la locura (...) $)^{19}$.

Más cerca aún de El Quijote - y sabemos que los erasmistas criticaron mucho en concreto los libros de caballerías, como le ocurriría también a Luis Vives- está este texto ${ }^{20}$ :

\footnotetext{
«Por lo demás, hay otro tipo de hombres que, sin ningún género de dudas, pertenece del todo a nuestra cofradía: son los que disfrutan con historias de prodigios y con fabulosas patrañas - tanto les da oírlas como explicarlas-y nunca tienen suficiente cuando se trata de rememorar no sé qué portentos referentes a espectros, aparecidos, fantasmas, seres infernales y millares de rarezas de esta clase, las cuales, cuanto más se apartan de lo verdadero, más a gusto son atendidas y con más delectable cosquilleo acarician los oídos (...)».
}

Pero notemos que aquí se está refiriendo una vez más a la stultitia (necedad) y no a la insania (locura), y además se trata más bien de una crítica de la superstición fantástica que sólo en algunos puntos podría tener relación con los libros de caballerías.

15 Op. cit., p. 181.

16 Op. cit., p. 185.

17 Cfr. op. cit., XXXVIII, pp. 189-95.

18 Op. cit., p. 193.

19 Pero insisto en que aquí locura es insania, distinta de stultitia.

20 Op. cit., XL, pp. 197-205, la cita en pp. 199-201. 
En fin, el libro de Erasmo es una genial obra maestra que contiene una gran crítica de la superstición religiosa ${ }^{21}$, y que defiende muchas veces lo contrario de lo que dice ${ }^{22}$, con su crítica de los escritores y poetas, la miseria de la vida del escritor etc. ${ }^{23}$. Realiza un repaso burlesco de todos los intelectuales, sobre todo de los filósofos ${ }^{24}$, los teólogos con los que se despacha a gusto ${ }^{25}$, etc. Es un libro muy moderno, irónico, anticlerical, con una defensa de la fe interior y partidario de una religión abierta, cuestiones todas sabidas de todo el mundo pero que quiero remarcar aquí.

Es terrible el conocido capítulo sobre los monjes ${ }^{26}$. Defiende la caridad como suma virtud expresando ya aquí su pensamiento directamente sin el artilugio de decir lo contrario de lo que piensa, para que resulte evidente. Ataca a los cortesanos, a los papas, cardenales y obispos, los sacerdotes, abandonando ya el sentido inverso para hacer más poderoso su alegato ${ }^{27}$. Frente a la religiosidad externa opone la interior ${ }^{28}$. Casi de un modo panteísta afirma que Dios absorbe hacia sí al hombre ${ }^{29}$. Y vuelve a la broma inversa cuando considera que los santos y las personas espirituales son dementes ${ }^{30}$. En fin: antes el necio era elogiado - en sentido inverso e irónico- y ahora los santos son dementes -es una paradoja: en realidad está elogiando a los santos y no a los necios-.

La obra de Erasmo es un prodigio de dobles sentidos y juegos irónicos de los que tal vez aprendió Cervantes, pero que está muy distante del modo de tratar nuestro escritor un tema como el de la locura que no es sobre el que propiamente versa el Elogio de la locura pese a su traducción castellana del término, por la anfibología o doble sentido del término antes señalada.

\section{El tema de la locura quijotesca}

Pero vayamos ya a las propias hipótesis interpretativas que voy a mantener aquí.

No voy a recorrer las páginas de El Quijote a propósito de la locura. Pero sí querría indicar, para iniciar este epígrafe en el que

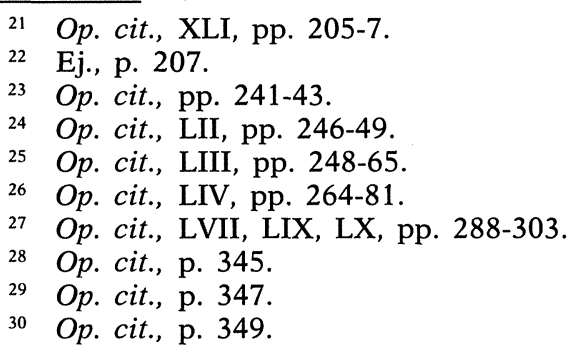


plantearé mi propia interpretación del tema de la locura quijotesca, que hay -entre otros muchos de esta obra inagotable - dos pasajes del libro que pueden ser esclarecedores para nuestro propósito:

En la Parte II capítulo XVIII, tras la sesuda conversación que ha mantenido Don Quijote con el Caballero del Verde Gabán, éste delega en su hijo el poeta para saber si está realmente loco, porque está admirado de sus elevadas razones. La conclusión que saca el hijo del Caballero del Verde Gabán, después de oírle a Don Quijote debatir acerca de la caballería andante es la siguiente:

«-No le sacarán del borrador de su locura cuantos médicos y buenos escribanos tiene el mundo: él es un entreverado loco, lleno de lúcidos intervalos».

Pero nótese que se ha estado dudando, por parte de Lorenzo y Don Diego, ya que Don Quijote alterna sesudas razones de elevada espiritualidad con la monomanía por la caballería andante, y en ella reside por tanto su locura obsesiva.

Antes, en la Parte I, capítulo XXXVII se contiene otra frase que merece la pena comentar:

«(...) de que no poco se admiraron y rieron, por parecerles lo que a todos parecía: ser el más extraño género de locura que podía caber en pensamiento disparatado».

Creo que esta frase resume el tema de la locura en la novela cervantina:

1. El narrador sirve de contraste y muestra la locura de Don Quijote.

2. "A todos parecía»: el individuo Don Quijote se posiciona frente al sentido común de todos, de donde su marginalidad y locura idealista.

2. "Locura extraña»: es una locura literaria, una ficción de la que el lector podrá extraer una enseñanza.

4. «Pensamiento disparatado»: la locura de Don Quijote no está constituida por la paranoia clínica. Frente a lo que se ha afirmado, no hay paranoia en nuestro personaje, que no se cree el centro, no es ególatra, no padece de complejo de persecución ni tiene problemas de autoestima ${ }^{31}$. La locura de Don Quijote es una locura literaria, de la que el lector puede reírse partiendo de la perspectiva

31 Cfr. David W. Swanson, Philip J. Bohnert y Jackson A. Smith, El mundo paranoide. Barcelona, Labor, 1974. El mejor trabajo que conozco sobre el tema de la paranoia clínica. 
realista del sentido común. Pero el contraste entre la visión disparatada de Don Quijote frente a la visión realista popular de Sancho, se enriquece en la Segunda Parte, cuando el narrador se ha encariñado de su personaje y nos transmite un amor enorme a su idealismo y a su locura.

5. La locura de Don Quijote se reduce a su obsesión por revivir los libros de caballerías. Pero, como veremos enseguida, de aquí se deduce una crítica de los valores caballerescos, con astucia para burlar la censura.

6. La locura de Don Quijote pasa de ser paródica en la Primera Parte a mostrarse como parte de la grandeza del personaje en la Segunda Parte - las escenas con los Duques etc.-, y hasta Sancho se contamina de ella, como tantas veces se ha dicho, con su obsesión particular por el gobierno de una ínsula y por el dinero.

7. El loco Don Quijote, se presenta como ejemplo de lo que no debe hacerse o es ridículo que se haga. Pero enseguida veremos que la crítica de Cervantes va más allá de los libros de caballerías -en donde era inocua - a plantearse como una crítica del ideal caballeresco, salvando la censura a través del personaje loco o bufón.

8. Don Quijote no sólo confunde realidad y fantasía, sino que vive una novela - la de Cervantes, El Quijote- pero tan real que nos referimos a él como a un ser vivo.

Ya en el prólogo de El Quijote Cervantes se burla de la cultura. Su libro se presenta como una burla y una ironía crítica de la cultura española de la época. Parece al principio que sólo pretende hacer reír, pero poco a poco va penetrando en su novela una fina ironía sobre estos aspectos.

Es un lugar común el afirmar que ya en el medioevo los bufones eran seres privilegiados a los que se permitía decir lo vedado a otros, paradigma por tanto de la libertad, hombres libres y sabios ${ }^{32}$.

En fin, quiero insistir que ante todo el loco es en El Quijote, el que dice y hace cosas que no están permitidas al resto de los ciudadanos, oprimidos por un rígido sistema social que era igual en España y en el resto de los países occidentales —olvidemos ya de una vez por todas la leyenda negra, o apliquémosla por igual a todos los países-. Este sistema era sin embargo permisivo a nivel popular, el pueblo incontrolable representado por Maritornes etc. Ya la relación entre amo y criado, entre Don Quijote y Sancho, está puesta en solfa por la locura del primero y la sensatez - aparente - del segundo.

32 Cfr. la conversación de Frida Ungern ilustrando a Lucas Corso en el capítulo XI de El Club Dumas de ARTURo Pérez-Reverte, si se quiere una referencia lúdica. 
Por tanto la locura es un modo de burlar la censura y una forma de marginalidad, según viera Tzvetan Todorov en su memorable Introduction à la littérature fantastique.

Notemos que El Quijote es al principio una obra grotesca, llena de sal gorda, en donde el protagonista recibe todos los palos risibles - por ejemplo I, cap. XVI, aventura de la venta-. Trata de despertar la hilaridad del lector con las burlas a Don Quijote, al que se zahiere y presenta como grotesco. Algunos escritores como Thomas Mann vieron lamentablemente sólo este primer aspecto plano en la obra de Cervantes. Pero poco a poco los personajes se agigantan en la mente del autor que les confiere una enorme gallardía ante el sufrimiento, los convierte en luchadores incansables ante la adversidad, en buscadores de sí mismos. Tras la aventura de Barcelona, hacia el final de la Segunda Parte, la obra tiene un pequeño momento de decaimiento y Cervantes sabe ha llegado ya al límite, retomando el vuelo al infinito con el desenlace final de la muerte de Don Quijote.

\section{Ideología y literatura en "El Quijote". Una interpretación de sentido de la novela cervantina}

Pero vayamos al núcleo de nuestra hipótesis interpretativa:

¿Cuál es, según creemos, la tesis fundamental de El Quijote?: que el idealismo es una locura, una sublimación errónea de la realidad, que es lo auténtico. Pero esta locura idealista - tan propia de la sociedad española - es entrañable y encantadora, constituye la sal de la realidad sin la que ésta se torna roma y rutinaria, de donde la complejidad de la obra.

La locura de Don Quijote es creerse el ideal caballeresco y no darse cuenta de la realidad que se impone como ineludible. Creo que era la misma locura que llevaba a los filósofos a pensamientos neoplatónicos de esencias inalcanzables - Dulcinea en la novela cervantina - cuando la realidad social venía marcada por el cólera, el hambre, la mendicidad, la guerra.

Y la locura de Don Quijote es una locura paródica, no propiamente locura, ya que pierde el juicio al leer los libros de caballerías. Se trata creo de un ariete contra la literatura establecida y la retórica de la época.

Porque, si la locura aparece como coartada para la crítica, ¿a qué se critica en El Quijote? Esto es lo que debemos averiguar.

¿Puede creerse que lo único que se critica en la novela cervantina son los libros de caballerías? ¿No es realmente inocua esta crítica? De hecho ya Juan Luis Vives ataca a los libros de caballerías de- 
fendiendo la novela bizantina de Heliodoro - Cervantes escribirá el Persiles después, novela bizantina dignificada- ${ }^{33}$. Erasmo y los erasmistas sabemos también atacaban a los libros de caballerías. ¿Se detuvo aquí en su crítica Cervantes, en criticar lo que todos criticaban?

Sabemos que Don Quijote parodia y ridiculiza a los libros de caballerías, que son los que le provocan la locura, y el vivir la realidad como una ficción -que constituye propiamente la novela de Cervantes-.

El Libro de la orden de caballería, escrito por Ramón Llull hacia 1275, del que poseemos una bella traducción de Luis Alberto de Cuenca, especialista y amante de los libros de caballerías ${ }^{34}$, me parece la base para comprender el espíritu de la caballería andante, tal y como se concebía en la Edad Media.

Podríamos establecer un nexo de unión entre el espíritu de los libros de caballerías y las leyes de la caballería andante, y el espíritu caballeresco de la sociedad española del Siglo de Oro. Soy consciente de que el punto débil de la base de la argumentación que voy a mantener enseguida radica en este punto. Pero veo factible esta asociación. Estudiando los artículos de El Censor escritos por Alberto Lista ${ }^{35}$, recalé en la comprensión por parte del escritor sevillano del espíritu caballeresco que latía en el teatro áureo que él defendió durante el trienio liberal. Sabemos hoy que ese espíritu caballeresco de los Siglos de Oro se basa en el concepto del honor, en la valentía, en la aristocracia espiritual, en el respeto a la mujer, en la necesidad de la decencia y discrección en ésta... en numerosos puntos de todos conocidos.

La cuestión que planteo es la siguiente: ¿Se puede realizar una asociación entre el espíritu de los libros de caballerías, y el espíritu caballeresco del Siglo de Oro español - patente en el teatro nacional de Lope y sus discípulos, luego en el de Tirso y Calderón-? Creo que sí. El concepto de caballero surge de un modo de vida a que debía ceñirse la existencia de los aristócratas medievales, reflejado en los libros de caballerías y por tanto heredado en el espíritu caballeresco del Siglo de Oro que hechizaba a Lista en la época romántica.

33 Cfr. de JUAN LuIS VIVES Institución de la mujer cristiana y De causis corruptarum artium (1524), estudiados por AMÉRICO CASTRO en El pensamiento de Cervantes. Madrid, 1925 , p. 60.

34 RAMÓN LLULL, Libro de la orden de caballería, introducción y traducción de Luis Alberto DE Cuenca. Madrid, Alianza, 1992 (LB, 1593).

35 Cfr. mi Ideología y literatura en Alberto Lista. Sevilla, Alfar, 1993, cfr. pp. 203336, espec. pp. 253-83. 
Si admitimos este salto, la cuestión de la parodia cervantina basada en la locura del protagonista cobra un nuevo vuelo: Don Quijote recorre en su viaje todas las clases de la sociedad del XVI, desde la baja a la alta, y las repasa de arriba abajo. Y lo que constituye el fundamento de su posición es -en la interpretación benigna- los excesos de los libros de caballerías - lo cual es inocuo para la censura, máxime, como se ha visto, al tratarse de un personaje loco que hace la crítica-. Pero cabe otra interpretación más cáustica, si bien El Quijote nunca descienda al terreno de la sátira o de la crítica agresiva y dura, sino que envuelve a todos los personajes en un manto de ternura, aunque sean prostitutas de venta u ociosos aristócratas ansiosos de diversión.

En definitiva lo que propongo es que El Quijote, soterrado en la crítica de los libros de caballerías, lo que hace en realidad es criticar y repasar la sociedad española del Siglo de Oro, y demostrar la inoperancia y anacronismo de los valores espirituales de dicha sociedad, que se basaban en los tópicos del espíritu caballeresco tal y como se representaban en el teatro nacional de Lope y sus seguidores.

Siguiendo este razonamiento resultaría que la locura de los libros de caballerías, sería la locura de la sociedad española de la época, cuyos valores se ponen en solfa o al menos se repasan desde sus cimientos. La locura es la de la sociedad española del XVI que transforma la realidad con la imaginación a través del código caballeresco creado desde la Edad Media (Llull, el Amadís primitivo, etc.)

La locura de Don Quijote, para Cervantes, reside en creer que el ideal caballeresco, que representaba la ideología española dominante de la época, podía hacerse realidad. Creo por tanto que lo que Don Quijote critica veladamente, bajo la apariencia inocua de censurar los excesos de los libros de caballerías, es a todo un sistema de vida contrarreformista, que daba un salto atrás por encima de los hallazgos ideológicos y liberadores del Renacimiento erasmista, para enlazar con los valores caballerescos medievales, tal y como se describían en el breve pero enjundioso Libro de la orden de caballería (1275) de Raimundo Llull.

Ahora se explica el concepto de amor provenzal en El Quijote -tan bellamente estudiado por Filgueira Valverde-, la idealización de la dama, el sentimiento del honor y la necesidad de reparación, la arrogancia imperial, el servicio a la dama... Todos los valores de la sociedad áurea se fundamentan en una visión democrática y masificada de los de las órdenes de caballería. Y Don Quijote no está poniendo en solfa sólo a los libros de caballerías, sino también a todos los valores caballerescos que fundamentan la sociedad que 
le tocó vivir, y que considera por tanto una locura, en cuanto apartados de la realidad. La visión de la futura decadencia española, que tan certeramente vería Quevedo, está aquí esbozada.

El Quijote sería, desde el punto de vista que planteo, el texto de crítica social e ideológica más fino de la época, y sin haber tenido ningún problema con la censura, precisamente por la locura del protagonista. Si Cervantes tuvo la suma habilidad de convivir en Argel con sus raptores sin necesidad de ser homosexual -es bobo pensar que fuera homosexual sólo por haber estado en cautiverio con raptores homosexuales-, también la tuvo para sortear la censura y reflejar la sociedad de su época de un modo entrañable y crítico a la vez, demostrando que el idealismo caballeresco que la sustentaba, conducía a la locura, a la evasión de la auténtica realidad, y por tanto, tarde o temprano, a la decadencia.

La locura de Don Quijote, por tanto, residiría en creer que el ideal caballeresco - que representaba la base de la ideología española oficial de la época- podía hacerse realidad. El Quijote no es así una obra hipócrita y contrarreformista como pensó Castro, sino el texto de crítica social más fina de la época, lo que no obsta para las infinitas interpretaciones que ha despertado y despertará siempre.

Creo que Cervantes ensaya el estilo idealista "comme il faut", propio del status de la época, en La Galatea y luego - con mejor prosa- en el Persiles. Pero la novedad de Cervantes en El Quijote reside en su estilo-verdad que rompe la apariencia de ficción y se sitúa a medio camino entre el estilo idealista - que parodia en numerosas ocasiones - y el bajo de la picaresca -que él también recreó en otra obra de arte: Rinconete-. Cervantes adopta en El Quijote la actitud verista del hombre de la calle frente a la literatura caballeresca idealista y los valores caballerescos que representa. Si en el Persiles vuelve a la ficción, El Quijote es una obra-verdad. Don Quijote mismo es también un hidalgo, que está a medio camino de lo alto y lo bajo, y expone la España oficial que su clase vertebra y a la que parodia.

Aunque deba advertirse que El Quijote es algo más que el reflejo de una clase social: constituye un personaje-verdad que supera su dimensión paródica para hacerse vida, la vida que todos los lectores de aquella época y de modo distinto los de las siguientes comprendían.

Insisto en que en El Quijote el punto de vista del narrador reside en la plasmación de la realidad directa y cotidiana, frente a la fantasía literaria de su personaje. Constituye así literatura de la literatura, metaliteratura. Don Quijote vive en una novela, en un libro de caballerías, y al mismo tiempo la novela por la que deambula 
-el corpus de El Quijote- constituye una ironía sobre estos libros en base al contraste entre realidad y fantasía, de donde el tema de la locura, la locura literaria.

El Quijote salta más allá de la ficción literaria a la que volverá Cervantes en el Persiles. En él se sintetizan dos características propias de la cultura y literatura españolas de todas las épocas: por una parte nuestro idealismo congénito; por otra su verismo - que no realismo-, su ser verdad, de donde que la nuestra sea la cultura más hipercrítica y autocrítica del universo. Por ello Ana Ozores es más verdad que Madame Bovary. Cervantes se salta los tipos literarios, la distancia de la ficción, y entrega la verdad entrañable, la vida. Es la clave de que El Quijote sea leído con pasión por lectores próximos al siglo XXI y que tenga una lectura diferente para cada crítico.

A destacar en El Quijote la relación democrática que tiene con Sancho, poco frecuente seguramente entre un hidalgo y un proletario. Porque como quería desde otro sentido Benjumea, Don Quijote es también un símbolo. Lo veo como reflejo de la amistad posible entre dos clases sociales. De aquí a la pretendida homosexualidad hay un abismo, aunque el que los críticos hagan lecturas modernas - si bien equivocadas, creo- de la obra, refleja su vitalidad, su capacidad de despertar ideas y adaptarla a los nuevos tiempos.

Más allá de su sentido, en la forma, El Quijote cautiva también por la elegancia de su estilo, tan pronto reflejo de un lenguaje popular lleno de poesía, tan pronto elevándose a la culta retórica caballeresca a la que dota de un nuevo espíritu, igualmente poético y humano.

En El Quijote la retórica se transforma en espiritualidad, humanidad y poesía. La realidad que se refleja lo hace a través de un tejido del lenguaje de una consistencia particular. Es la elegancia caballeresca del universo español de finales del siglo XVI, más valioso creo que el de los libros de caballerías que son un despropósito de batallas y amores, con la excepción entre otras del Amadis de Montalvo. Y este mundo es siempre próximo al lector de todos los tiempos, pese a la diferencia de estilo y lenguaje, porque estamos ante una obra eterna, en la que los intereses de cada crítico y lector se ven como en un espejo.

En fin, quiero insistir finalmente en que El Qujote satiriza benignamente la manera caballeresca que era el código español de honor del Siglo de Oro. Cervantes ejemplifica así la esquizofrenia del pensamiento católico e imperial: la diferencia entre el ideal -que es a la vez una forma de sublimidad y de locura- y la realidad -la pobreza de la sociedad de finales del XVI-. Cervantes se burla por tanto de la Contrarreforma exponiendo los valores en que se funda- 
menta como una forma de locura, de esquizofrenia: el cielo o más allá religioso vendría representado por el ideal caballeresco, la ideología del Estado imperial; la tierra, la realidad social representada por Sancho.

De este modo la locura de Don Quijote no es la real y clínica, sino un instrumento de análisis para repasar con el salvoconducto bufonesco todas las clases sociales de la época sin temor a la Inquisición. La locura como instrumento de parodia bufonesca. La locura erasmista en el sentido de insania, no stultitia, según vimos. Medio de acceso a lo más recóndito, humano y entrañable de su personaje. Símbolo de que el ideal caballeresco del Siglo de Oro y la religión católica con su más allá, conducen a la esquizofrenia, separando el mundo ideal del real. Cervantes trata de unir estos dos mundos con la quijotización de Sancho y la sanchificación de Don Quijote señalada acertadamente por la crítica, en las que se supera la entelequia contrarreformista y se corrige con una mentalidad moderna.

La locura de Don Quijote le hace un ser vivo y cercano, en el que todo crítico se proyecta. Su intención de curar las injusticias del mundo le convierte en un filántropo, que es una forma de locura en un mundo egoísta. Don Quijote es un loco sabio, como se ve en el episodio con el Caballero del Verde Gabán, Don Diego.

Y, finalmente, el discurso que tiene Don Quijote en la cabeza es de una lógica peculiar, la del código caballeresco, pero tiene su lógica, que Cervantes encuentra tan admirable y humana como risible.

De este modo se constituye una obra genial y única, en la que creo se ironizan y critican los valores de la España oficial de la Contrarreforma, para destacar igualmente sus aspectos admirables, su dimensión de espiritualidad caballeresca. Se unen así parodia y lirismo, construidas con la poesía de un lenguaje popular y vivo como era el español de la época, para acceder a una dimensión crítica de una serie de valores que se contrastan con la realidad y se censuran a la vez que se admiran.

Esto es El Quijote desde mi propia perspectiva crítica ${ }^{36}$, como dice Cervantes «además de otras muchas cosas», porque esta novela constituye un poliedro infinito de inagotables reflejos y sentidos.

Diego MARTínez TORRón Universidad de Córdoba

${ }^{36}$ Cfr. las páginas preliminares con mi metodología crítica al inicio de mi Ideología y literatura en Alberto Lista. Sevilla, Alfar, 1993, pp. 9-25, que aplico en este trabajo. 